\title{
Treatment of electroplating wastewaters
}

\author{
Larisa Belova ${ }^{1}$, Elena Vialkova $^{1}$, Ekaterina Glushchenko ${ }^{1,}{ }^{*}$, Viacheslav Burdeev ${ }^{1}$, and \\ Yuriy Parfenov ${ }^{1}$ \\ ${ }^{1}$ Industrial University of Tyumen, Department of Water Supply and Sewage, Volodarskogo Street 38, \\ Tyumen, 625000, Russia
}

\begin{abstract}
In this article, the specificity of wastewaters formed at electroplating plants and problem of its treatment is considered. The purpose of this research is to suggest the technological scheme of wastewater treatment, for one of the typical electroplating plants. Standard research methods were used: gravimetrical, photometrical and fluorimetrical methods of liquid analysis to achieve this goal. This article presents the method of electroplating wastewater treatment, based on chemical precipitation, including addition of the various reagents for removing heavy metals from the effluents. Because of the laboratory research, the effects of pollutants removal are $91 \%$ (total iron) and $94.6 \%$ (suspended solids). These effects were achieved by the technological scheme that includes averaging and mixing several technological effluents, their chemical precipitation with $\mathrm{NaOH}, \mathrm{Ca}(\mathrm{OH})_{2}$ and flocculant during an hour.
\end{abstract}

\section{Introduction}

Contamination of the water bodies by industrial wastes, for example, by partially or untreated wastewaters, negatively impacts biosphere and human health [1].

Intensive development of economic activity, as well as industrial infrastructure, influences environment [1]. In addition, electroplating manufactories are no exception.

Electroplating is an industry, involving the deposition of the protective and decorative layers on the metal or non-metal surfaces. Electroplating industry is one of the most hazardous sources of environmental pollution due to a large amount of the formed wastewaters, containing the high concentrations of the heavy metals (copper $\mathrm{Cu}$, iron $\mathrm{Fe}$, nickel $\mathrm{Ni}$, cadmium $\mathrm{Cd}$, chromium $\mathrm{Cr}$, aluminium $\mathrm{Al}$, lead $\mathrm{Pb}$, zinc $\mathrm{Zn}$ and others), acids, alkalis, organic compounds and surfactants. The presence of one or another heavy metal ion depends on kind of technological process on the manufactory as well as function of galvanic coating [2-3].

According to the statistics, on the territory of Russian Federation there are about 7000 electroplating plants. Electroplating industry is large consumer of the non-ferrous metals and expensive chemical agents. The facilities consume about $15 \%$ of nickel, $50 \%$ of zinc and $70 \%$ of copper, extracted in Russia.

\footnotetext{
*Corresponding author: ekaterina.gluschenko.1997@mail.ru
} 
The technological processes of electroplating wastewater treatment are classified according to the reactions and chemical composition of the electrolytes, which are the source of wastewater forming. Consequently, the operations on the electroplating manufactories can be divided into 4 groups according to 4 wastewater types [3]:

1) the operations, forming the solutions or rinse waters, which include the cyanide compounds - the main processes of galvanizing and washing after these solutions;

2) the operations, forming the solutions or rinse waters, which include the chromium compounds - the main processes of chrome-plating, chromium passivation and washing after these solutions;

3) the operations, forming the solutions or rinse waters, which include the heavy metal ions - the main processes of electrochemical metal reduction and washing after these solutions;

4) the operations, forming the solutions or rinse waters, which do not include the abovementioned compounds - the minor works (degreasing, etching).

A large amount of the Russian and foreign researches investigate and introduce into electroplating plants the possible technological schemes of wastewater treatment, directed to removing the heavy metals, organic compounds and $\mathrm{pH}$ stabilization.

For example, at wastewater treatment plants (WWTP) of enterprise "Manotom", Tomsk, Russia, firstly, the hexavalent $\mathrm{Cr}^{6+}$ is reduced to non-toxic trivalent $\mathrm{Cr}^{3+}$ by adding the sodium pyrosulphate to wastewater. After this wastewater is sent to mixing chamber, where $\mathrm{pH}$-index is become 8.5-9 for forming the chromium hydroxide $\mathrm{Cr}(\mathrm{OH})_{3}$, and then to settling tank, where flocculant is added to. After treatment, the clarified wastewater is dumped into industrial sewage system [4]. The wastewater treatment effectiveness from heavy metal according to such scheme is about $80 \%$.

In USA, the Company "New Logic Research" [5] suggests using the vibratory membranes for rejection of the heavy metal ions from wastewater. Unique technology $\mathrm{V} \diamond \mathrm{SEP}$ is based on oscillating movement of the membrane surface with respect to the filtered wastes. As a result, the membrane surface is cleaned due to the solid particles and free access to the membrane pores to the filtered liquid fraction is provided. The vibratory shear leads to suspended and colloidal solids repelling and their holding in suspension above the membrane surface.

The Vietnam researches [6] suggest technological scheme of electroplating wastewater treatment, which includes the initial treatment of the different liquid wastes types, their further mixing, averaging and reagent neutralizing. After settling, the clarified wastewater can be dumped into the sewage systems or water objects.

One of the famous methods of heavy metals removal from wastewaters is electrocoagulation [7-10]. Due to this method it can be possible to remove the metal ions such as $\mathrm{Cu}^{2+}, \mathrm{Cr}^{6+}, \mathrm{Cr}^{3+}, \mathrm{Ni}^{2+}$ and $\mathrm{Zn}^{2+}$. The iron, aluminum or graphite electrodes can be used as an anode and cathode while electrocoagulation. All authors mention the pHinfluence on the process of the metals precipitation and reduction from wastewater. According to the researches, the optimal $\mathrm{pH}$ for metals removing is 4-8. The $\mathrm{pH}$-index increase in solution is caused, mostly, by the cathode reactions. In addition, in all science works, almost total metals removing from electroplating wastewater is achieved.

Another widespread way of heavy metal reduction is chemical precipitation [11-14]. In this case, the soluble ions of heavy metals are transformed into insoluble maters (for example, hydroxides) using various reagents. During precipitation the prior task is the $\mathrm{pH}$ regulation and its maintaining (usually, it is alkaline conditions). For maintenance of the alkaline conditions in wastewater, the various alkaline reagents (sodium hydroxide, potassium hydroxide, caustic lime and others) are used. Besides, these reagents provide transformation of the metals ions to the insoluble hydroxides, which, further, can be removed from water by settling and filtration. 
According to the investigations [12-14], the optimal $\mathrm{pH}$-value for metals precipitation by lime $\mathrm{Ca}(\mathrm{OH})_{2}$ is higher than 9.5 . The metal concentrations during it were decreased on $85-99 \%$. The flocculant adding $\left(0.5 \mathrm{mg} / \mathrm{dm}^{3}\right)$ increase the effectiveness of metal reduction [13].

Among the new modern methods of heavy metals removal from wastewaters the membrane technologies (such as ultrafiltration, nanofiltration, reverse osmosis, electrodialysis), as well as ion exchange technologies are well-known [15-23]. For improving selectivity of the membrane, different polyelectrolytes are used [17], which are able to change the membrane surface charge density, its hydrophilicity and fouling resistivity. The following materials can be used as polyelectrolytes: polystyrene sulfonate, polyallylamine hydrochloride, polyacrylic acid and others.

In conjunction with the foregoing, the aim of this science works is the research of wastewater qualitative composition, as well as suggestion of the possible technological scheme for WWPT at the electroplating manufactory.

\section{Materials and methods}

The technological activity of the galvanic manufacture at Electrode Plant, located in Tyumen region (Russia), leads to the formation of three wastewaters' types:

- $\quad$ spent soap solution (S);

- $\quad$ spent concentrated acid effluent (A);

- $\quad$ wastewater from rinse of the metal products $(\mathrm{R})$.

All these wastes are characterized with high degree of the irregularity, and are dumped in the various periods, depending on technological process at the plant. According to this fact, the research was conducted for the most adverse conditions, when all three types of wastes are dumped. Wastes were sampled separately, mixed together in proportions, and then sent to laboratory for wastewater treatment modeling.

Based on manufactory technological specificity, in initial and treated wastewater, the following qualitative indices were measured: $\mathrm{pH}$, suspended solids, chemical oxygen demand (COD), total iron and anionic surfactants.

Wastewater's $\mathrm{pH}$ was potentiometrically measured by the $\mathrm{pH}$-meter $\mathrm{pH}-150 \mathrm{MI}$.

Suspended solids were measured according to the mass difference between paper filter before and after filtration by the gravimetric method.

Chemical oxygen demand (COD) was photometrically measured on the fluid analyzer "Fluorat-02" after heating the mixture of the wastes, potassium dichromate, mercury sulphate, silver sulphate in sulfuric acid during two hours at $150^{\circ} \mathrm{C}$.

Total iron was measured photometrically on spectrophotometer PE-5400VI. The wastewater samples with $0.5 \mathrm{~cm}^{3}$ of nitric acid were evaporated, then $2 \mathrm{~cm}^{3}$ of ammonium chloride, salycil-sulphonic acid and ammonia were added. After samples' cooling the concentration of total iron was determined.

The concentration of anionic surfactants was fluometrically determined on the fluid analyzer "Fluorat- 02 " by their chloroform extraction from wastewater in the presence of acridine yellow.

\section{Results and Discussions}

The results of the laboratory research on wastewater qualitative composition are shown in Table 1. 
Table 1. The qualitative composition of initial wastewater.

\begin{tabular}{|c|c|c|c|c|}
\hline \multirow{2}{*}{ Index } & \multirow{2}{*}{ Unit of measurement } & \multicolumn{3}{|c|}{ Sample } \\
\cline { 3 - 5 } & & $\mathrm{S}$ & $\mathrm{S}+\mathrm{A}$ & $\mathrm{S}+\mathrm{A}+\mathrm{R}$ \\
\hline $\mathrm{pH}$ & - & 1.58 & 0.9 & 0.87 \\
\hline Suspended solids & $\mathrm{mg} / \mathrm{dm}^{3}$ & 382 & 1256 & 2566 \\
\hline Chemical oxygen demand (COD) & $\mathrm{mgO} / \mathrm{dm}^{3}$ & 220 & 1937 & 4560 \\
\hline Total iron & $\mathrm{mg} / \mathrm{dm}^{3}$ & 607.5 & 667.5 & 667.5 \\
\hline Anionic surfactants & $\mathrm{mg} / \mathrm{dm}^{3}$ & - & - & 220 \\
\hline
\end{tabular}

Due to the high concentrations of total iron and low $\mathrm{pH}$, reagent treatment of wastewater was chosen as the first stage of treatment. The following reagents were added to wastewater:

- $\quad 10-\%$ solution of sodium hydroxide $\mathrm{NaOH}$;

- $\quad 5-\%$ solution of lime $\mathrm{Ca}(\mathrm{OH})_{2}$;

- $0.1-\%$ solution of flocculant "Superfloc A-100" for improvement of formed hydroxides precipitation.

The $\mathrm{NaOH}$-dose for reaching $\mathrm{pH}$-value 9-10 at the water samples was experimentally found, and this dose was $206 \mathrm{ml} / \mathrm{l}$. The dose of $\mathrm{Ca}(\mathrm{OH})_{2} 40 \mathrm{ml} / 1$ was taken; the dose of flocculant $5 \mathrm{ml} / 1$ was taken.

The initial wastewater was put into the laboratory cylinders of $0.5 \mathrm{dm}^{3}$ capacity, where abovementioned reagents in optimal doses were added to. After mixing wastewater and added reagents, solution was settled during 60 minutes. After passing an hour the required qualitative indices were measured in clarified water (Figure 1 and Figure 2).

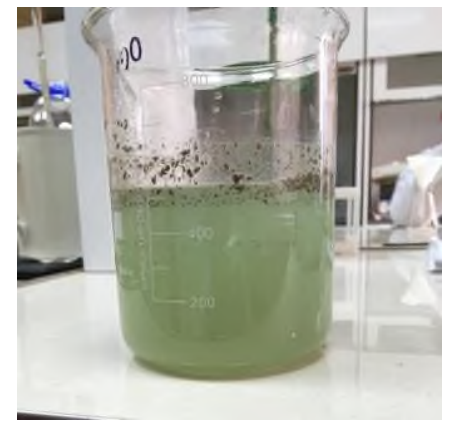

Fig. 1. Initial wastewater, which is the mixture of several technological effluents.

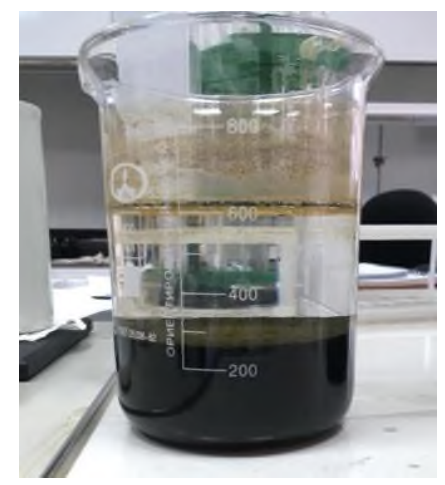

Fig. 2. The wastewater sample after 60-minutes reagent precipitation. 
During settling the formation and sedimentation of dark green sludge, which volume was about $40 \%$ from total sample volume, was observed. The research results on qualitative composition of clarified wastewater are shown in Table 2.

Table 2. The qualitative composition of clarified wastewater after reagent precipitation

\begin{tabular}{|l|c|c|}
\hline \multicolumn{1}{|c|}{ Indices } & Unit of measurement & Measurement results \\
\hline $\mathrm{pH}$ & - & 11.49 \\
\hline Suspended solids & $\mathrm{mg} / \mathrm{dm}^{3}$ & 96 \\
\hline Total iron & $\mathrm{mg} / \mathrm{dm}^{3}$ & 23.5 \\
\hline
\end{tabular}

\section{Conclusions}

Thus, according to the conducted research the following conclusions have been made:

- Wastewater that formed at electroplating manufactory has the high concentrations of the heavy metals, organic compounds, low $\mathrm{pH}(1-5)$ and it is characterised by high degree of irregularity.

- Using the alkaline reagents (potassium hydroxide and lime) for reducing heavy metal concentrations, $\mathrm{pH}$ stabilization and intensification of precipitation by adding flocculant allow to reach the high efficiency of the total iron reduction on $91 \%$ and suspended solids reduction on $94.6 \%$.

- The optimal technological schemes of electroplating wastewater treatment are suggested (Figure 3 and Figure 4). The type of scheme depends on required wastewater treatment quality.

\section{Effluents}

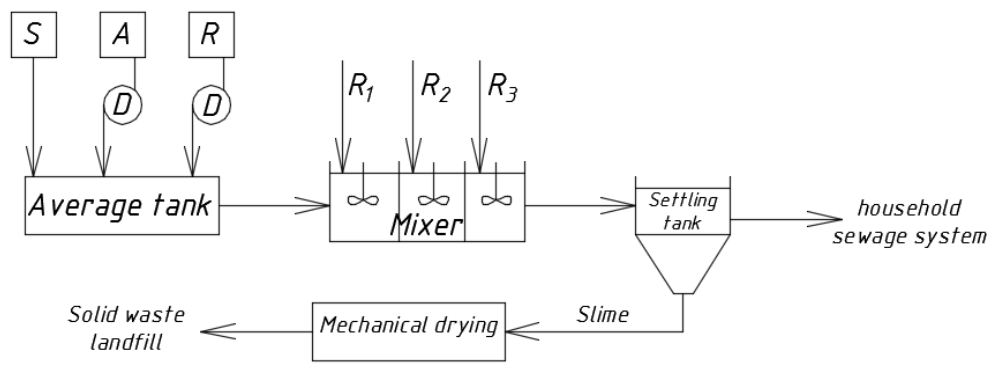

Fig. 3. The technological scheme of wastewater treatment, dumped into the domestic sewage system: $\mathrm{S}$ - waste soap solution, A - concentrated acid effluent, $\mathrm{R}$ - rinse wastewater, $\mathrm{D}$ - dosing pump, $\mathrm{R}_{1}$, $\mathrm{R}_{2}, \mathrm{R}_{3}$ - added reagents.

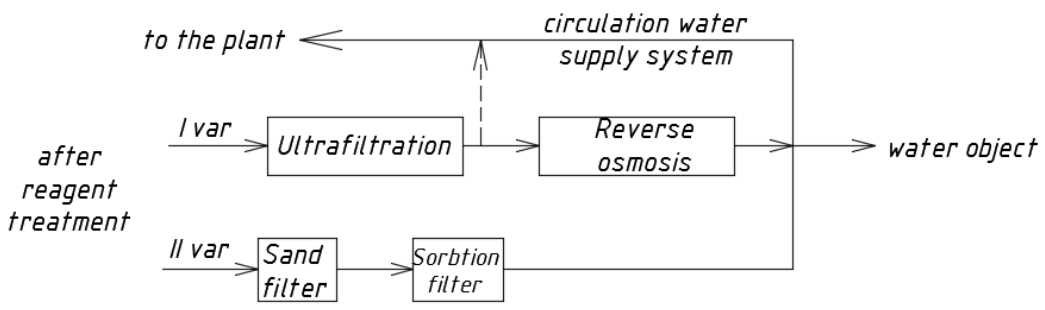

Fig. 4. The technological scheme of wastewater treatment, dumped into water object or reused in the electroplating technological operations. 


\section{References}

1. V.I. Il'in, A.F. Gubin, Astrahanskij vestnik ekologicheskogo obrazovaniya, Minimization of negative effect of electroplating industry on an environment, 3, 55-60 (2014). (rus)

2. Studies in Environmental Science Chapter 13 Waste Water from Chemical and Electrochemical Metal-Treatment Processes, 187-215 (1979). DOI: 10.1016/s01661116(08)71604-2

3. K. Upadhyay, Jr. of Industrial Pollution Control, Solution for wastewater problem related to electroplating industry: an overview, 22, 59-66 (2006).

4. A.Yu. Batalova, O.V.Nazarenko, Energetika: effektivnost', nadezhnost', bezopasnost': materialy XX Vserossijskoj nauchno-tekhnicheskoj konferencii Ochistka stochnyh vod gal'vanicheskogo proizvodstva ot tyazhelyh metallov na primere OAO «MANOTOM'», 2, 136-138 (2014). (rus)

5. Membrane Filtration of Metal Plating Wastewater https://www.vsep.com/pdf/MetalPlating.pdf

6. K. Do, J. Walder SF Journal of Environmental ad Earth Science An Evaluation of technologies for Reduction of Wastewater from Plating Industry in Vietnam, 1 1-8 (2018).

7. N. Adhoum, L. Monser, N. Bellakhal, J.-E. Belgaied, Journal of Hazardous Materials Treatment of electroplating wastewater containing $\mathrm{Cu}^{2+}, \mathrm{Zn}^{2+}$ and $\mathrm{Cr}(\mathrm{VI})$ by electrocoagulation., 112, 207-213 (2004). DOI: 10.1016/j.jhazmat.2004.04.018

8. M. Al-Shannag, Z. Al-Qodah, K. Bani-Melhem, M. Rasool Qtaishat, M. Alkasrawi Chem. Eng. J., Heavy metal ions removal from metal plating wastewater using electrocoagulation: Kinetic study and process performance, 260, 749-756 (2015). DOI: 10.1016/j.cej.2014.09.035

9. G. Chen Sep. Purif. Technol. Electrochemical technologies in wastewater treatment, 38 11-41 (2004). DOI: 10.1016/j.seppur.2003.10.006

10. F. Akbal. S.Camc, Desalination. Copper, chromium and nickel removal from metal plating wastewater by electrocoagulation, 269, 214-222 (2011). DOI: 10.1007/s12205014-0642-8

11. A. Azimi, A. Azari, M. Rezakazemi, M. Ansarpour ChemBioEng Rev, Removal of Heavy Metals from Industrial Wastewaters: A Review, 4, 1-24 (2017). DOI: 10.1002/cben.201600010

12. T.A. Kurniawan, G.Y.S. Chan, W.-H. Lo, S.Babel, Chem. Eng. J. Physico-chemical treatment techniques for wastewater laden with heavy metals, 118, 83-98 (2006). DOI: 10.1016/j.cej.2006.01.015

13. L. Charemtanyarak Water Sci. Technol., Heavy metals removal by chemical coagulation and precipitation, 39, (1999). DOI: 10.1016/S0273-1223(99)00304-2

14. Q. Chen, Z. Luo, C. Hills, G. Xue, M. Tyrer, Water Research, Precipitation of heavy metals from wastewater using simulated flue gas: Sequent additions of fly ash, lime and carbon dioxide, 43, 2605-2614 (2009). DOI: 10.1016/j.watres.2009.03.007

15. B.A.M. Al-Rashdi, D.J. Johnson, N. Hilal, Desalination. Removal of heavy metal ions by nanofiltration, 315, 2-17 (2013). DOI: 10.1016/j.desal.2012.05.022

16. A.W. Mohammad, Y.H. Teow, W.L. Ang, Y.T. Chung, D.L. Oatley-Radcliffe, N. Hilal, Desalination. Nanofiltration membranes review: Recent advances and future prospects, 356, 226-254 (2015). DOI: 10.1016/j.desal.2014.10.043 
17. L. Y. Ng, A. W. Mohammad, C. Y. Ng, Adv. Colloid Interface Sci., A review on nanofiltration membrane fabrication and modification using polyelectrolytes: Effective ways to develop membrane selective barriers and rejection capability, 197, 85-107 (2013). DOI: 10.1016/j.cis.2013.04.004

18. S.S. Shenvi, A.M. Isloor, A.F. Ismail, Desalination, A review on $R O$ membrane technology: Developments and challenges, 368, 10-26 (2015). DOI: 10.1016/j.desal.2014.12.042

19. S.H. Joo, B. Tansel, Journal of Environmental Management, Novel technologies for reverse osmosis concentrate treatment: A review, 150, 322-335 (2015). DOI: 10.1016/j.jenvman.2014.10.027

20. S.-Y. Kang, J.-U. Lee, S.-H. Moon, K.-W. Kim, Chemosphere. Competitive adsorption characteristics of $\mathrm{CO}^{2+}, \mathrm{Ni}^{2+}$, and $\mathrm{Cr}^{3+}$ by IRN-77 cation exchange resin in synthesized wastewater, 56, 141-147 (2004). DOI: 10.1016/j.chemosphere.2004.02.004

21. F. Gode, E. Pehlivan, Journal of Hazardous Materials. Removal of chromium(III) from aqueous solutions using Lewatit S 100: The effect of $p H$, time, metal concentration and temperature. 136, 330-337 (2006). DOI: 10.1016/j.jhazmat.2005.12.021

22. A. Dąbrowski, Z. Hubicki, P. Podkościelny, E. Robens, Chemosphere Selective removal of the heavy metal ions from waters and industrial wastewaters by ionexchange method 56, 91-106 (2004). DOI: 10.1016/j.chemosphere.2004.03.006

23. N. Martynov, et al. Pulsed electric discharge in an aqueous medium for processing raw amber. Journal of Physics: Conference Series 1614, 012060 (2020) doi:10.1088/1742$6596 / 1614 / 1 / 012060$ 